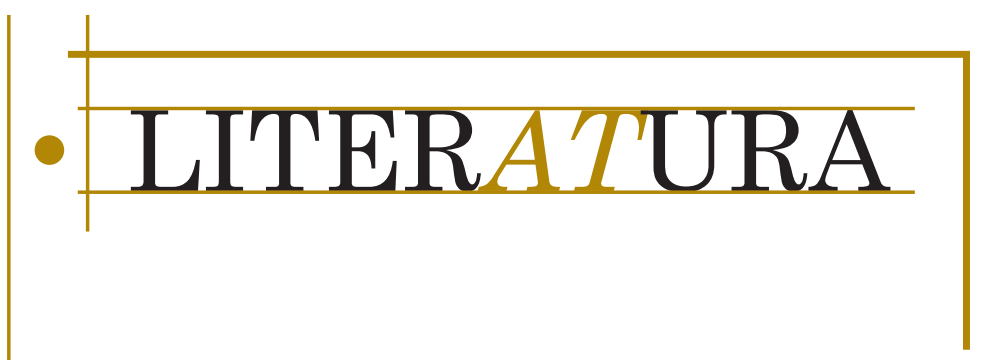




\section{A AMEAÇA DO FANTÁSTICO EM A CHAVE DO TAMANHO, DE Monteiro Lobato}

\section{Felipe Teixeira Zobaran* Cecil Jeanine Albert Zinani**}

Resumo: Este artigo busca analisar a presença do elemento insólito em $A$ chave do tamanho, de Monteiro Lobato (1997). Parte-se de Roas (2014), que, em diálogo com Todorov (2007), considera que o gênero fantástico propõe a desconstrução (negação) da realidade, como uma ameaça. Zilberman (1982), ao analisar o Sítio do Picapau Amarelo, sistematiza-o como um universo neutro que propõe a desestabilização ao leitor. Isso fica especialmente claro em A chave do tamanho, livro que trata de temas muito adultos da época de publicação (1942). Conclui-se que a crítica de Lobato sobre tais temas é feita, justamente, pelo efeito da literatura fantástica como vista por Roas (2014).

Palavras-chave: Literatura fantástica. Monteiro Lobato. Literatura brasileira.

\section{INTRODUÇÃO} político brasileiro de seu tempo. Nascido em 1882, o escritor viu acontecerem fatos de grande importância para a história contemporânea nacional e mundial. Perto do fim de sua vida, nos anos 1940, viu-se compelido a expressar-se a respeito do que seria o ápice dos conflitos do ideário de sua geração: a Segunda Guerra Mundial. Segundo Cytrynowicz (2000), Lobato foi um dos poucos autores literários brasileiros a abordar diretamente o tema. A grande guerra é, de fato, o pontapé inicial da narrativa intitulada $A$ chave do tamanho, publicada originalmente em 1942.

O presente trabalho busca, pois, analisar os mecanismos utilizados por Lobato para construir o enredo dessa obra. Trata-se de um romance voltado ao públi-

\footnotetext{
Universidade de Caxias do Sul (UCS) - Caxias do Sul - RS - Brasil. E-mail: ftzobaran@gmail.com

** Universidade de Caxias do Sul (UCS) - Caxias do Sul - RS - Brasil. E-mail: cezinani@terra.com.br
} 
co infantojuvenil, parte constituinte da coleção do seu Sítio do Picapau Amarelo ${ }^{1}$. Com pano de fundo de fantasia, o texto versa sobre temas do mundo real.

Segundo Roas (2014), em diálogo com a obra de Todorov (2007), essa é, justamente, a característica primordial do fantástico literário: ele não existe senão em contraponto com o mundo real. O autor espanhol, base para este estudo, afirma que a literatura fantástica tem forte potencial para propor análises críticas e questionamentos a respeito da realidade (empírica e teórica), pois propõe a suspensão arbitrária das fronteiras entre o real e o sobrenatural. Também contribuem teoricamente os estudos escritos e organizados por Zilberman (1982) e Valente (2008), importantes para a consolidação da pesquisa sobre a produção de Monteiro Lobato nos últimos anos.

O gênero fantástico é, tecnicamente, tão antigo quanto a produção ficcional, mas os estudos a seu respeito são relativamente recentes. Segundo Roas (2014, p. 29), "ainda não contamos com uma definição que considere em conjunto as múltiplas facetas disso que demos por chamar literatura fantástica". Espera-se que este trabalho contribua para a maturação dessa produção teórica. Além disso, é inegável a importância de Monteiro Lobato para a literatura (infantil) brasileira, o que justifica a pertinência de abordagens de sua obra sob diferentes pontos de vista.

Este artigo constitui-se, inicialmente, de reflexões teóricas a respeito da estética do gênero literário fantástico. A seguir, propõe-se a analisar o enredo de $A$ chave do tamanho, sob esse ponto de vista teórico. Por fim, objetiva mapear relações entre o enredo, o universo interno do romance e seu contexto sócio-histórico.

\section{A PERDA DA SEguranÇA}

Tzvetan Todorov, filósofo, linguista e teórico literário búlgaro, buscou definir o fantástico literário, em sua obra Introdução à literatura fantástica, lançada, originalmente, em 1970. Embora muitos teóricos tenham tentado fazê-lo anteriormente, a reunião de vozes e a nova proposta criada por Todorov no fim do século XX tornaram-se referência para a crítica posterior no tocante à classificação do gênero fantástico - que extensivamente vem relendo e revisando o que ele propôs.

Todorov (2007) busca definir o "fantástico" na literatura. Ele propõe, inicialmente, que um gênero só existe a partir do momento em que ele pode reunir um grupo finito de características comuns a todos os textos que possam ser classificados dentro dele. Assim, não se trata de um pensamento por inferência, uma vez que seria impossivel conhecer todos os textos que pudessem ser classificados como pertencentes ao gênero fantástico, mas por dedução, ou seja, devem-se primeiro definir as propriedades do fantástico para posteriormente aplicá-las a textos existentes e decidir se eles pertencem ou não ao gênero. Dessa forma, a primeira regra para que um texto seja considerado fantástico é que haja uma hesitação entre a realidade e o sobrenatural (TODOROV, 2007, p. 30-40). Essa hesitação deve incidir sobre o leitor, que, de maneira guiada pela narrativa ou não, passa a questionar se os fatos narrados são do mundo real, de um mundo

\footnotetext{
Para este trabalho, optou-se pela grafia da palavra "picapau" sem hífen, seguindo a tradição das publicações e reedições dos livros lobatianos. De acordo com o Acordo Ortográfico de vigência obrigatória a partir de 2016, o animal "pica-pau" é grafado com hífen.
} 
mágico, do além-morte, da loucura, da droga etc. Enquanto a dúvida permanece, o texto fantástico está íntegro. E é por esse motivo que Todorov (2007, p. 38) separa o gênero fantástico da alegoria, por exemplo:

[...] existem narrativas que contêm elementos sobrenaturais sem que o leitor jamais se interrogue sobre sua natureza, sabendo perfeitamente que não deve tomá-los ao pé da letra. Se animais falam, nenhuma dúvida nos assalta o espírito: sabemos que as palavras do texto devem ser tomadas num outro sentido, que se chama alegórico.

A alegoria, juntamente com a poesia (lírica e alegórica), para Todorov (2007), é responsável por "matar" o fantástico. Ele parte do pressuposto de Quintiliano de que uma alegoria é uma metáfora continuada, e da retórica de Fontanier, que defende que a alegoria sempre tem duplo sentido, acrescentando a ideia de que a alegoria à qual ele se refere é um duplo sentido entre literal e figurado, "indicado na obra de maneira explícita: [que] não depende da interpretação (arbitrária ou não) de um leitor qualquer" (TODOROV, 2007, p. 71), uma vez que

[...] não se pode falar em alegoria a menos que dela se encontrem indicações explícitas no interior do texto. Senão, passa-se à simples interpretação do leitor; por conseguinte, não existiria mais texto literário que não fosse alegórico, pois é próprio da literatura ser interpretada e reinterpretada infinitamente por seus leitores (TODOROV, 2007, p. 81).

Como exemplos desse embate, Todorov traz diversos autores. Em alguns deles, o fenômeno é bastante evidente, como os textos de Charles Perrault, contos de fada que seguem a base estrutural das fábulas e que, logo após a narrativa (apinhada de eventos e seres sobrenaturais), o próprio narrador deixa explícito que todos os acontecimentos devem ser tomados como representativos de uma moral da história. Contudo, o teórico búlgaro prevê a existência de textos com alegoria "indireta" e "hesitante", exemplificados pela produção de autores como Hoffmann, Balzac e Edgar Allan Poe.

Um terceiro grau no abrandamento da alegoria encontra-se na narrativa em que o leitor chega a hesitar entre interpretação alegórica e leitura literal. Nada no texto indica o sentido alegórico; contudo, esse sentido permanece possível (TODOROV, 2007, p. 76).

Isso gera problemas claros.

Seguindo a perspectiva todoroviana, textos como "William Wilson", de Poe, não fazem parte do gênero fantástico, porque a alegoria, mesmo que não indicada no texto, é fortemente possivel (TODOROV, 2007, p. 75). Isso abre precedentes para se afirmar que o mesmo aconteceria, então, com a produção de Cortázar, Borges, Gabriel García Márquez, juntamente com todos os escritores contemporâneos constituintes ou próximos ao Realismo Maravilhoso, bem como os textos de autores oitocentistas, como é o caso de Machado de Assis, no Brasil, com contos como "O espelho", e diversas outras manifestações literárias que tratam do insólito, mas têm grande potencial alegórico.

O teórico búlgaro propõe, ainda, que um texto deve ser classificado como fantástico apenas enquanto mantiver a hesitação entre a realidade e o sobrenatural em curso (TODOROV, 2007, p. 47-52). Quando essa hesitação termina, o gênero se altera; se o mistério é resolvido e os fatos narrados são explicados por 
fatores do mundo real (como acontece nos romances policiais, ou em relatos sobre loucura e drogas, por exemplo), lida-se com o gênero estranho (termo derivado do conceito freudiano de unheimlich). A "literatura estranha" tem como maiores expoentes aqueles autores que conseguem criar um efeito de incômodo, questionamento ou hesitação na narrativa, mas que não cedem a uma lógica mágica ou sobrenatural, como faz a narrativa de Dostoiévski.

Contrapondo-se a isso, quando o efeito de hesitação do fantástico cede lugar a explicações completamente mágicas ou sobrenaturais, adentra-se no gênero maravilhoso. O maravilhoso se aproxima da narrativa mítica, lendária ou religiosa, no sentido de não questionar uma lógica que está além do mundo real. Isso acontece na maior parte dos contos de fada, dos textos de ficção científica, histórias de fantasma e em textos de fantasia.

Ainda que Todorov (2007, p. 50-55) considere a existência de gêneros intermediários (fantástico estranho, fantástico maravilhoso), não é difícil perceber que, em sua teoria, o fantástico nada mais é do que uma fronteira fugaz, ou, segundo David Roas (2014, p. 41), uma “categoria evanescente que se definiria pela percepção ambígua que o leitor implícito tem dos acontecimentos relatados". O autor espanhol busca, em produção contemporânea que leva em conta o percurso da teoria e da crítica desde Todorov ${ }^{2}$, uma definição mais englobadora do que seria considerado como literatura fantástica.

Roas $(2014$, p. 31) defende que "a narrativa fantástica põe o leitor diante do sobrenatural, mas não como evasão, e sim, muito pelo contrário, para interrogá-lo e fazê-lo perder a segurança diante do mundo real". O fantástico, nesse ponto de vista, não é apenas uma hesitação, mas uma transgressão da realidade. O texto fantástico vale-se do "real" para ameaçá-lo, desconstruí-lo, questioná-lo. Se há fantástico, há perda de segurança da realidade.

O universo do Sítio do Picapau Amarelo baseia-se no elemento insólito ${ }^{3}$. Lobato construiu, ao longo de sua obra, um espaço povoado por seres e elementos sobrenaturais, constantemente em contato com personagens e lugares de múltiplas histórias constituintes do imaginário ocidental. Regina Zilberman (1982, p. 39-44) observa que o Sítio é um ambiente privilegiado. Lobato precisou construí-lo para pôr em prática seu projeto de consolidação de uma literatura infantil que alcançasse o público brasileiro. Se antes a criança brasileira tinha contato principalmente com a tradição oral vinda da Europa, via península Ibérica, já tão desvinculada de referências regionais devido às adaptações sofridas ao longo dos séculos, a partir da produção de Lobato, é possivel afirmar que há, na prática, uma literatura infantil brasileira. Ele foi capaz de converter o imaginário infantil ocidental em texto acessivel linguística e culturalmente à criança do Brasil.

Mas o que torna o Sítio um ambiente privilegiado é a sua configuração própria. Trata-se de um lugar "neutro" (ZILBERMAN, 1982, p. 41), pois ele acolhe e, ao mesmo tempo, resiste tanto ao mundo da fantasia quanto ao mundo real. Esse ambiente é constituído por seres fantásticos e reais (os protagonistas são a boneca falante humanizada, Emília, o sabugo de milho que ganhou vida à Pinóquio, Visconde de Sabugosa, os animais falantes, os primos Narizinho e Pedrinho e os adultos, a avó Dona Benta e a criada Tia Nastácia). Em meio à fantasia,

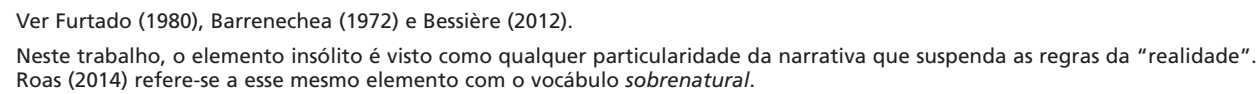


Lobato propõe clara representatividade da realidade sócio-histórica da época de produção e recepção dos livros.

Por vezes, o ambiente padrão do Sítio é ultrapassado e surge uma "viagem" ou um "portal" que remete os personagens a mundos completamente maravilhosos. Zilberman (1982, p. 42-44), ao analisar o livro O Picapau Amarelo, no qual o sítio é invadido por personagens do "Mundo-da-fábula", confirma que há uma divisão entre o Sítio e o maravilhoso completo, mesmo quando personagens batem à porta de Dona Benta. Para abrigá-los, a senhora compra novos hectares e os denomina Terras Novas. Cercados e chaveados, os personagens só podem entrar em contato com os protagonistas quando permitido. Assim, permanecem existindo os limites entre a realidade (do Sítio) e o mundo maravilhoso.

Por outro lado, em muitos momentos, há ecos da realidade nacional nas narrativas. Todo o contexto subentendido é compativel com aquele da fazenda interiorana submetida à política do café-com-leite, e há, em diversos pontos da obra completa, representações de elementos da sociedade da época: coronéis, prefeitos, policiais, carteiros, fatos mundiais e menções pontuais a livros, cidades e personalidades. Esses elementos, entretanto, são quase completamente exteriores ao território do Picapau Amarelo. Zilberman (1982, p. 39) sinaliza que, na estrutura social dos enredos do Sítio, não se representam as estruturas sociais mais básicas da sociedade brasileira da primeira metade do século XX. A autora considera que a escola, a igreja e a família burguesa tradicional patriarcal são subvertidas por Lobato. Pedrinho está em férias constantes, quase não se menciona a doutrina católica, e a propriedade é liderada por uma mulher idosa, sem que haja figura patriarcal. Há, pois, também, uma divisão entre o mundo real da época de Lobato e o Sítio. Essa estrutura lógica pode ser representada como no Quadro 1.

Quadro 1 - Estrutura do universo ficcional do Sítio do Picapau Amarelo

\begin{tabular}{|l|l|l|}
\hline \multicolumn{1}{|c|}{ Mundo real } & \multicolumn{1}{|c|}{$\begin{array}{c}\text { Sítio do Picapau } \\
\text { Amarelo }\end{array}$} & \multicolumn{1}{c|}{ Mundo-da-fábula } \\
\hline $\begin{array}{l}\text { Burocracia, estrutura so- } \\
\text { cial patriarcal, igreja, esco- } \\
\text { la, contextos da época de } \\
\text { produção (primeira metade } \\
\text { do século XX). }\end{array}$ & $\begin{array}{l}\text { Animais falantes, Emília, } \\
\text { Visconde de Sabugosa, fa- } \\
\text { cilidade de começar aven- } \\
\text { turas com o cruzamento de } \\
\text { "portais". }\end{array}$ & $\begin{array}{l}\text { Personagens do imaginário } \\
\text { ocidental, terras distantes, } \\
\text { lógica maravilhosa. }\end{array}$ \\
\hline
\end{tabular}

Fonte: Elaborado pelos autores com base em Zilberman (1982, p. 38-41).

O Sítio do Picapau Amarelo, enquanto ambiente "neutro", pode, então, ser considerado um ambiente de "hesitação". Trata-se do lugar fantástico todoroviano por excelência: em toda a obra infantil de Lobato, o leitor e os personagens veem-se vacilantes entre um mundo e outro; a realidade brasileira da primeira metade do século XX (dentro e fora do Sítio), o universo fantástico maravilhoso e o maravilhoso puro (também dentro e fora do Sítio).

O Sítio também parece ser um espaço fantástico ao se levar em conta o que defende David Roas (2014, p. 54). A visão do autor espanhol sobre o fantástico poderia ser esquematizada de maneira muito parecida com aquela de Zilberman a respeito da estrutura do Sítio do Picapau Amarelo: 


\section{Quadro 2 - Estrutura do fantástico roasiano}

\begin{tabular}{|l|l|l|}
\hline \multicolumn{1}{|c|}{ Texto realista } & \multicolumn{1}{|c|}{ Texto fantástico } & \multicolumn{1}{c|}{ Texto maravilhoso } \\
\hline $\begin{array}{l}\text { Não há transgressão do } \\
\text { mundo real, uma vez que } \\
\text { narra a realidade em ape- } \\
\text { nas um plano. }\end{array}$ & $\begin{array}{l}\text { Há transgressão, uma vez } \\
\text { que representa o sobrena- } \\
\text { tural dentro do real e faz } \\
\text { questionar os limites da } \\
\text { realidade. }\end{array}$ & $\begin{array}{l}\text { Não há transgressão com o } \\
\text { mundo real por existirem } \\
\text { planos incontestavelmente } \\
\text { distintos. }\end{array}$ \\
\hline
\end{tabular}

Fonte: Elaborado pelos autores com base em Roas (2014, p. 53-55).

De fato, em sua estratégia de aproximação dos contos de fada antigos para o leitor brasileiro, Lobato exerce a função de situar os personagens e o leitor na especificidade do interior rural brasileiro do início do século XX, embora não a abrace tão completamente a ponto de desfazer a "universalidade" ${ }^{4}$ das narrativas infantis orais de origem europeia que lhe servem de matéria-prima ${ }^{5}$. Ele constrói narrativas cujo universo básico é composto também pela hesitação entre elementos localizados e descontextualizados no tempo-espaço.

\section{A Perda do tamanho}

Um dos textos lobatianos que mais se pautam em fatos do universo real da época de produção é A chave do tamanho, de 1942 (ZILBERMAN, 1982, p. 42). A história inicia-se com Emília incomodada pela tristeza de Dona Benta; a Inglaterra acabara de ser bombardeada pela Alemanha nazista, e o futuro do contexto político mundial estava incerto. Já no início da narrativa, os vínculos entre o mundo real e o universo fantástico do Sítio são estreitados.

Aquela tristeza de Dona Benta andava a anoitecer o Sítio do Picapau, outrora tão alegre e feliz. E foi justamente essa tristeza que levou Emília a planejar e realizar a mais tremenda aventura que ainda houve no mundo. Emília jurara consigo mesma que daria cabo da guerra e cumpriu o juramento - mas por um triz não acabou também com a humanidade inteira (LOBATO, 1997, p. 9).

De fato, valendo-se do superpó (variante mais potente do antigo pó de pirlimpimpim que funciona, ao longo da história, de maneira similar aos "portais" das narrativas maravilhosas), Emília viaja até o fim do mundo e chega a uma espécie de casa de chaves do funcionamento da realidade. Sua intenção é "desligar" a guerra, mas há incontáveis chaves na sala e nenhuma delas é identificada. A boneca decide, então, desligar a primeira que vê e, acidentalmente, causa a diminuição do tamanho de toda a humanidade. Imediatamente, ela própria (que se tornara mais humana do que boneca), vê-se envolta em muitos panos gigantescos, suas antigas roupas. Ao conseguir sair, não é capaz de religar a

4 Considera-se que o termo "universal" possa ser controverso, uma vez que toda obra ficcional é dotada de regionalidade, mesmo que via expressão de características do imaginário e do ideário de seus contextos de produção e recepção. Com base em Haesbaert (2010, p. 8-20), o vocábulo "universalidade" poderia ser lido como ocidentalidade, internacionalidade ou supra-regionalidade.

5 A obra infantil lobatiana não propõe narração do maravilhoso completo. Esse ocorre, por exemplo, em contos de fada, nos quais o "Era uma vez..." exclui, de início, qualquer relação com o plano do mundo real (ROAS, 2014, p. 32). Na necessidade de classificação da obra lobatiana em consonância com Todorov (2007), o mais racional parece ser considerar a narrativa toda como fantástico-maravilhosa, pois há momentos e lugares de hesitação entre real e sobrenatural, mas, em última instância, as explicações são de ordem mágica. 
chave do tamanho, por ser, agora, muito leve e pequenina. Com um restolho de superpó, ela retorna às cercanias do Sítio e logo se vê em meio a uma floresta gulliveriana de matagais e monstros gigantescos, os antigos jardins e insetos em nova perspectiva.

A aventura inicia-se, então, evidenciando a desgraça de muitos homens que não conseguem se adaptar a situações adversas. Com discurso assumidamente darwinista, fica evidente a necessidade de mudança de pontos de vista defendida pela narração. Alguns humanos morrem sufocados pelas próprias roupas; outros, comidos pelos bichos de estimação; muitos, especialmente os adultos, com ideias preconcebidas, são incapazes de perceber que diminuíram de tamanho. Pensam, ao contrário, que tudo a seu redor aumentou - uma alegoria pontual que se conecta com o início do livro, quando os personagens discutem sobre o fato de, apesar de o Sol "nascer" e "se pôr", é a Terra que gira ao redor do astro. Trata-se da necessidade de mudança de paradigmas para que haja percepção científica.

Em sua aventura rumo ao Sítio, Emília é acompanhada por duas crianças vizinhas, Juquinha e Candoca, cujos pais acabam sendo comidos pelo gato da família. Eles são leitores dos livros do Sítio do Picapau Amarelo e, por isso, conhecem a boneca: “- É a Emília mesmo, mamãe! - gritou um menino que também andava por ali e só então ela viu. - Conheço os livros que falam dela. A cara é a mesma, o jeito é o mesmo. Só falta a roupinha de xadrez" (LOBATO, 1997, p. 23). Trata-se de um exemplo de aproximação do universo fantástico "neutro" do Sítio com a realidade de recepção da obra lobatiana.

Se Roas (2014) afirma que o fantástico serve para ameaçar, desestabilizar a realidade, a perda do tamanho é um bom exemplo desse efeito. Valente (2008, p. 457-458) sinaliza que, como crianças, os pequenos adultos passam a ver as coisas por novos pontos de vista, o que instaura uma nova ordem no mundo humano. Desnudos (não apenas figurativamente), os novos homens veem-se forçados a relativizar tudo aquilo que conheceram e criaram; e as reflexões propostas pelo narrador (e possibilitadas pela história) são de fundo extremamente existencial.

Emília logo é encontrada pelo Visconde de Sabugosa que, por ser vegetal, não diminuiu de tamanho. Os dois discutem sobre o novo contexto e decidem que a mudança talvez pudesse ser benéfica para a humanidade. De fato, com o fim do tamanho, a guerra acabara, e, com ela, todos os outros maleficios criados pela humanidade. O fim do tamanho fazia o papel da seleção natural: somente os aptos sobreviveriam, somente aqueles que, como Emília, fossem capazes de utilizar-se do universo natural ao seu redor (insetos como meio de transporte, alimento vindo de flores e mel, roupas de algodão) subsistiriam ao cataclismo instaurado. Se a sociedade permanecesse como anteriormente, o planeta acabaria superlotado, ou o homo sapiens terminaria por se autodestruir. Talvez fosse mesmo o caso de haver uma nova ordem.

Após se encontrarem com os habitantes do Sítio, Visconde e Emília (que agora habitava o interior da cartola do amigo vegetal, convertida em casa) decidem viajar pelo mundo com o resto do superpó, com fins de averiguar os efeitos do apequenamento em outras terras. A tragédia ocorreu, de fato, em todas as partes do planeta. Os dois personagens chegam primeiramente a Berlim, na Alemanha, e o que veem é uma cidade morta, cheia de montinhos de roupa abandonados. Sem demora, caminham até o palácio do governo nazista. 
O Visconde analisa:

- Aqui morava o ditador que levou o mundo inteiro à maior das guerras, e destruía cidades e mais cidades com os seus aviões, e afundava os navios com os seus submarinos, e matava milhares e milhares de homens e canhões com suas metralhadoras - o homem mais poderoso que jamais existiu. Tudo isso por quê? Porque tinha oito palmos e meio de altura. Assim que foi reduzido a quatro centímetros, todo seu poder evaporou-se. Ele, se é que ainda não foi para o papo de algum pinto sura, permanece o mesmo, com a mesma energia mental, a mesma disposição destruidora e a mesma vontade de aço - mas não pode mais nada (LOBATO, 1997, p. 67).

E, de fato, o Führer não havia sido devorado por nenhum "pinto sura". Os dois personagens o encontram dentro da fresta de um móvel, escondido, e reconhecem-no pelo bigode. Emília toma a oportunidade para falar com o grande ditador e dar-lhe uma bronca por querer dominar e destruir o mundo. O mesmo ocorre na próxima viagem, quando há uma visita à Cidade Imperial no Japão, no palácio do imperador.

A manobra de Lobato é sutil; o discurso de Emília é veemente, mas suave (em tom adequado para uma obra de literatura infantil) ${ }^{6}$. A questão da comunicação em diferentes linguas é suspensa (como em um universo maravilhoso), mas o objetivo é claro: tornar o sólito insólito, o personagem real, adulto, poderoso, subjugado pelo ser fantástico da literatura infantil. Novamente, há uma inversão de perspectiva, uma quebra de paradigma.

O narrador de Lobato prossegue na construção dessa ideia com um exemplo positivo. A próxima parada de Visconde e Emília é um ponto dos Estados Unidos em que a nova humanidade pequenina já começou a se organizar em sociedade. Pail City, a cidade do balde, é constituída por um grupo de sobreviventes que já construiu abrigo, organizou um sistema de alimentação - caça de minhocas - e que, liderado pelo esclarecido antropólogo Doutor Barnes, aproveita a visita do Visconde e de Emília para enriquecer sua nova organização. A etapa final da viagem dos personagens lobatianos é a Casa Branca. Lá, eles encontram o presidente e os ministros dos Estados Unidos. Sobre a representação norte-americana por Lobato, Valente (2008, p. 461) expõe:

[...] a fartura comprovada pelas experiências do dr. Barnes, em Pail City [...], tem seu contraponto na miséria e no sofrimento causados pela guerra. A relação que se estabelece entre grande/pequeno, perto/longe diz respeito tanto à tensão entre essas formas de ser, quanto à interdependência entre elas. Resistência, higiene, funcionalidade, aspectos de Pail City, uma cidade comandada pela ciência, não pela politicagem ignorante dos homens "tamanhudos", ou seja, um novo parâmetro de vida com mais qualidade que os homens poderão, agora, buscar entre os insetos, velhos conhecedores do mundo pequenino.

A grande sugestão da obra é, de fato, a possibilidade (insólita) de a humanidade organizar-se em uma sociedade perfeita, recomeçando do zero. Como sugere Zilberman (1982, p. 44), Lobato, com seu espaço neutro que se comunica 
ao mesmo tempo com o real e o maravilhoso, propõe uma utopia, na qual os aspectos negativos da realidade podem ser subvertidos.

\section{O FILÓSOFO CHINÊS}

Antes mesmo da viagem de Emília e Visconde pelo mundo, Dona Benta põe-se a analisar a situação que havia acometido a humanidade. A sábia senhora traz à tona, então, o "caso do filósofo chinês".

- Aquele filósofo ou poeta chinês, já não me lembro, que passou a noite sonhando que era borboleta, e durante todo o sonho viveu a vida das borboletas, com ideiazinhas de borboleta, comidinhas de borboleta, tudo de borboleta, com a maior perfeição. Quando acordou e se viu outra vez homem, caiu na dúvida. "Serei uma borboleta que está sonhando que é homem ou sou um homem que sonhou que era borboleta?" E por mais que pensasse nisso, nunca pôde saber com certeza se era realmente uma borboleta que sonhava ser homem ou um homem que havia sonhado ser borboleta (LOBATO, 1997, p. 63).

Em uma alusão que remete tanto ao nonsense de Alice no País das Maravilhas quanto à proposta de inversão de realidades de Dom Quixote, Lobato, na voz de Dona Benta, ajuda o leitor a refletir sobre a composição da própria realidade. É um efeito consonante com o fantástico roasiano, que possibilita uma ameaça ao real. Também o é a proposta de $A$ chave do tamanho, a mudança utópica de paradigmas que a nova ordem impõe sobre a humanidade. Com o fim do tamanho, os homens precisam abandonar toda a sujeira que haviam criado, dentre elas, a guerra.

Todavia, na conclusão do enredo, o tamanho volta. Emília e o Visconde retornam ao sítio e, democraticamente, propõem um plebiscito. As crianças, com suas cabeças jovens e revolucionárias, defendem que a pequenez permaneça. Os adultos, retrógrados e conservadores, querem a realidade que conheciam de volta. Por fim, quem decide é o Visconde, com seu voto de Minerva. O sábio vegetal tem, então, suas considerações narradas; neutro como o pensamento científico, precisou considerar os dois lados. Decide pelo tamanho para que não fosse mais domado por Emília, que havia tomado sua cartola e decidido suas ações nos últimos dias, como uma grande ditadora ${ }^{7}$. Os dois, com a ajuda do superpó, vão novamente à casa das chaves do mundo e trazem o tamanho de volta à humanidade.

Zilberman (1982, p. 44) coloca que

[...] Lobato, como Emília, esta mais uma vez seu alter ego ficcional, precisa aceitar que os homens não mudaram seu tamanho e que a guerra-ou a rivalidade entre as grandes potências - continuava cada vez mais aguda. Portanto, não podia trapacear com a realidade, que era sua e do leitor. De modo que, mesmo sonegando-a ou tentando modificá-la, não pôde evitar uma cobrança ulterior. E esta veio sob forma de uma estética - a do realismo, a que mesmo o gênero para crianças precisa se sujeitar, sob pena de pôr a perder sua validade literária. Configura-se nestes termos o perímetro do círculo dentro do qual se desenvolve a criação de Lobato abrigando dentro dele não apenas um modelo de mundo imaginário, mas também a opção estética que permite traduzi-lo.

\footnotetext{
Valente (2008) sugere que o discurso ditatorial de Emília ilustra em si a relativização de valores proposta pela obra. "Uma personagem autoritária - uma ditadora discursando para ditadores?" (VALENTE, 2008, p. 466). O autoritarismo latente de Emília, em todo o livro é usado para lutar contra os ditadores alemão e japonês. A mentira, a ameaça infantil e a fantasia são utilizadas para desconstruir um mundo que, no fim das contas, é feito mesmo de mentiras e desilusões.
} 
Depois de permitir que as forças maravilhosas da sala das chaves mudassem até mesmo a realidade exterior à do Sítio, alcançando não apenas os líderes políticos da época como também os leitores dos livros publicados por Lobato próprio, o autor sente-se na necessidade de retornar ao perimetro que criara. O Sítio permanece sendo um ambiente neutro, entre o real e o maravilhoso, e, mesmo quando essa fronteira é extrapolada, ao fim, ela precisa ser reafirmada. Afinal, o mundo real não deixa de existir. A guerra e a incapacidade humana permanecem.

Na voz de Valente (2008, p. 466), “a obra mais 'louca' de Lobato é, justamente, aquela em que a realidade do momento se mostra mais pulsante, apontando-nos uma relatividade não explícita no texto, mas mesmo assim importante: a relação ficção-realidade". É um enredo cuja direção opõe-se à aventura fantástica tradicional. Diferentemente de Gulliver, Crusoé ou Alice, Emília viaja até o seu próprio mundo; a diferença está em sua constituição, sua posição e, consequentemente, no ponto de vista. É o mundo próprio habitado pelo leitor da obra, mas ele está às avessas. O confronto utópico de Lobato é para com a realidade que o cerca, e a perda do tamanho é como a perda da segurança roasiana.

Mais do que teorizar sobre a guerra, a estupidez humana, o darwinismo, a superpopulação da Terra, o pensamento conservador e o discurso revolucionário, Lobato propõe, em A chave do tamanho, uma ameaça à conformidade com o real. E isso se dá pela configuração fantástica de seu Sítio do Picapau Amarelo.

\section{CONSIDERAÇÕES FINAIS}

A literatura fantástica tem, em sua própria configuração, potencial de desconstrução da realidade (ROAS, 2014). O elemento sobrenatural ajuda o leitor a perder a segurança; isso, em última instância, possibilita novas percepções, posicionamentos críticos em face do status quo.

Completamente vinculado a seu tempo, Monteiro Lobato propôs, em sua obra infantil, desconstrução similar. Com um Sítio do Picapau Amarelo perfeitamente neutro (ZILBERMAN, 1982), no sentido de ser um entre-mundos no limiar da realidade e do maravilhoso puro, o autor conseguiu, ao mesmo tempo, trazer o faz de conta para a proximidade do leitor brasileiro e vincular a realidade brasileira a esse mesmo mundo do faz de conta. Via insólito, com um universo vezes muito realista, vezes às avessas, o leitor de Lobato, mesmo criança, tem contato com reflexões de fundo filosófico e político e com análises profundas de realidades não tão infantis, como a Segunda Guerra Mundial.

O elemento fantástico roasiano tem, pois, em Lobato, potencial função de instigar mentes novas. Ao dar voz ao "pequenino", relativizam-se pontos de vista e, consequentemente, propõe-se certa emancipação (da criança em relação ao adulto, do interior em relação à capital, do Brasil em relação ao mundo, do novo em relação ao velho...). E as chaves do mundo movem-se com ideias novas.

\section{Fantastic literature as a threat in A chave do tamanho, by Monteiro lobato}

Abstract: This article aims at analyzing elements of the fantastic literary genre in A chave do tamanho (meaning The swich of size), by Brazilian author Monteiro Lobato (1997). The starting point is Roas (2014), who, complementing Todorov 
(2007), defines the fantastic as the literature that promotes a denial of reality. Zilberman (1982) considers Lobato's fictional setting, O Sitio do Picapau Amarelo, as a neutral universe, since it is neither placed in the real nor in the magic world, but in between. A chave do tamanho is a book that deals particularly with the adult reality of its publication time (1942). Lobato's critical considerations about such themes are delivered precisely due to his use of fantastic elements as defined by Roas (2014).

Keywords: Fantastic literature. Monteiro Lobato. Brazilian literature.

\section{REFERÊNCIAS}

BARRENECHEA, A. M. Ensayo de uma tipologia de la literatura fantástica. Revista Iberoamericana, v. 38, n. 80, p. 391-403, jul./set. 1972. Disponível em: <http://revista-iberoamericana.pitt.edu/ojs/index.php/Iberoamericana/article/view/2727/2911>. Acesso em: 25 mar. 2016.

BESSIÈRE, I. O relato fantástico: forma mista do caso e da adivinha. Fronteiraz, n. 3, p. 1-18, jul. 2012. Disponivel em: <http://revistas.pucsp.br/index.php/ fronteiraz/article/view/12587>. Acesso em: 25 mar. 2016.

CYTRYNOWICZ, R. Guerra sem guerra: a mobilização e o cotidiano em São Paulo durante a Segunda Guerra Mundial. São Paulo: Geração Editorial, Edusp, 2000.

FURTADO, F. A construção do fantástico na narrativa. Lisboa: Livros Horizonte, 1980.

HAESBAERT, R. Região, regionalização e regionalidade: questões contemporâneas. Antares: Letras e Humanidades, Caxias do Sul, n. 3, p. 2-24, jan./jul. 2010.

LOBATO, M. A chave do tamanho. 43. ed. São Paulo: Brasiliense, 1997.

ROAS, D. A ameaça do fantástico. In: ROAS, D. A ameaça do fantástico: aproximações teóricas. São Paulo: Editora Unesp, 2014.

TODOROV, T. Introdução à literatura fantástica. São Paulo: Perspectiva, 2007.

VALENTE, T. A. A chave do mundo: o tamanho. In: LAJOLO, M.; CECCANTINI, J. L. (Org.). Monteiro Lobato livro a livro: obra infantil. São Paulo: Editora Unesp, 2008.

ZILBERMAN, R. Monteiro Lobato e a aventura do imaginário. Letras de Hoje, Porto Alegre, n. 49, p. 35-46, set. 1982. 